\title{
RELAP5 Code Study of ROSA/LSTF Experiments on PWR Safety System Using Steam Generator Secondary-Side Depressurization
}

\author{
Takeshi Takeda ${ }^{1}$, Akira Ohnuki ${ }^{2}$ and Hiroaki Nishi ${ }^{3}$ \\ 1. Japan Atomic Energy Agency, Ibaraki-ken 319-1195, Japan \\ 2. Mitsubishi Heavy Industries, Ltd., Hyogo-ken 652-8585, Japan \\ 3. The Kansai Electric Power Co., Inc., Fukui-ken 919-1141, Japan
}

Received: January 29, 2015 / Accepted: March 04, 2015 / Published: May 31, 2015.

\begin{abstract}
RELAP5 (reactor excursion and leak analysis program, version 5) code analyses were performed on two ROSA/LSTF (rig of safety assessment/large scale test facility) experiments on PWR (pressurized water reactor) safety system that simulated cold leg small-break loss-of-coolant accidents with 8-in. or 4-in. diameter break using SG (steam generator) secondary-side depressurization. The SG depressurization was initiated by fully opening the depressurization valves in both SGs immediately after a safety injection signal. In the 8-in. break test, loop seal clearing occurred and then core uncovery and heatup took place by core boil-off. Core collapsed liquid level recovered after the initiation of accumulator coolant injection, and long-term core cooling was ensured by the actuation of low-pressure injection system. In the 4-in. break test, on the other hand, there was no core uncovery and heatup due to smaller break flow rate than in the 8-in. break test. Adjustment of Cd (break discharge coefficient) for two-phase discharge flow predicted the break flow rate reasonably well. The code well predicted the overall trend of the major thermal-hydraulic response observed in the two LSTF tests by the Cd adjustment. The code, however, overpredicted the peak cladding temperature because of underprediction of the core collapsed liquid level due to inadequate prediction of the accumulator flow rate in the 8-in. break case.
\end{abstract}

Key words: PWR, safety system, ROSA/LSTF, small-break loss-of-coolant accident, SG depressurization, RELAP5 code.

\section{Nomenclature}

$\begin{array}{ll}\text { ACC } & \text { Accumulator } \\ \text { BETHSY } & \text { Boucle d'etudes thermohydraulique systeme } \\ \text { Cd } & \text { Break discharge coefficient } \\ \text { LOBI } & \text { Loop off-normal behavior investigations } \\ \text { LPI } & \text { Low-pressure injection } \\ \text { LSTF } & \text { Large scale test facility } \\ \text { PCT } & \text { Peak cladding temperature } \\ \text { PKL } & \text { Primärkreisläufe versuchsanlage } \\ \text { PWR } & \text { Pressurized water reactor } \\ \text { RELAP5 } & \text { Reactor excursion and leak analysis program, } \\ \text { ROSA } & \text { version 5 } \\ \text { SG } & \text { Rig of safety assessment } \\ & \text { Steam generator }\end{array}$

\section{Introduction}

In light of the lessens learned from station blackout

Corresponding author: Takeshi Takeda, senior researcher, research fields: thermal hydraulics and nuclear safety. E-mail: takeda.takeshi@jaea.go.jp. accident of the Fukushima Dai-ichi reactor [1], it is important to line up various cooling measures for reactor core and containment. The PWR (pressurized water reactor) electric utilities and vender, etc. in Japan [2] are progressing to develop a reliable alternative safety measure to cool the reactor core under a small-break loss-of-coolant accident of a PWR using SG (steam generator) secondary-side depressurization [3] by means of steam discharge through the SG depressurization valves, as shown in Fig. 1. In the research, it is aimed to promote an early activation of ACC (accumulator) system of emergency core cooling system to assure the core cooling by an early SG depressurization even under loss of core cooling functions by high-pressure injection system of emergency core cooling system. The feasibility study 


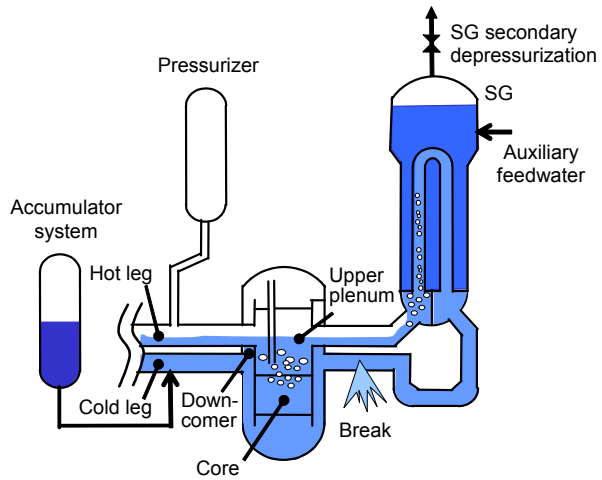

Fig. 1 Coolant behavior during PWR cold leg small-break loss-of-coolant accident with steam generator secondary-side depressurization.

of the safety measure then is being performed with the LSTF (large scale test facility) [4], where full-pressure simulation can be achieved, in the ROSA (rig of safety assessment) program at Japan Atomic Energy Agency since 2011. The LSTF simulates a Westinghouse-type four-loop 3,423 MW (thermal) PWR by a full-height and 1/48 volumetrically-scaled two-loop system.

The SG depressurization is also one of major accident management measures to cool and depressurize the primary system during a small-break loss-of-coolant accident for the existing PWRs. There have been several simulation tests with the LSTF on the SG depressurization as the accident management measure where each test was done under certain conditions of the SG depressurization start and rate considering a grace period for the onset and a procedure of an operator action $[5,6]$. Moreover, some experimental data on the accident management measure have been obtained by using other integral test facilities with such atypical features as small volume and low pressure in the primary system. The SG depressurization was initiated at a scram signal in a test with the LOBI (loop off-normal behavior investigations) in Italy [7], while, it was started when the cladding surface temperature reached a certain temperature in a test with the BETHSY (boucle d'etudes thermohydraulique systeme) in France [8]. The SG depressurization rate was controlled to achieve a certain primary depressurization rate in both the tests. The SG depressurization was performed by fully opening SG relief valves when the core exit temperature reached a certain temperature in a test with the PKL (primärkreisläufe versuchsanlage) in Germany [9]. The onset timing and rate of the SG depressurization as the accident management measure, however, were different from those as the PWR safety system described below.

For each ROSA/LSTF experiment on the PWR safety system, the SG depressurization was initiated by fully opening the depressurization valves in both SGs immediately after a safety injection signal. Auxiliary feedwater injection was done into the secondary-side of both SGs about $2 \mathrm{~min}$ after the safety injection signal. Flow capacity of the SG depressurization valve at a certain SG secondary-side pressure was almost twice as that of a SG relief valve $[5,6]$, which can be used for the SG depressurization in the reference PWR of the LSTF. The ACC system was assumed to inject coolant into a cold leg in the loop with pressurizer only to achieve the core cooling conservatively. Coolant from LPI (low-pressure injection) system of emergency core cooling system was injected into vessel downcomer through direct vessel injection lines [10] in both loops.

In this study, two ROSA/LSTF tests on PWR cold leg small-break loss-of-coolant accidents with 8 -in. or 4-in. diameter break were analyzed by RELAP5 (reactor excursion and leak analysis program, version 5)/MOD (modification)3.2.1.2 code [11] to well understand observed thermal-hydraulic phenomena and to validate the code predictability. Core uncovery and heatup took place by core boil-off in the 8-in. break test while no core uncovery and heatup occurred in the 4-in. break test (to be described in Sections 4.1.1 and 4.2.1). For the evaluation of the safety measure effectiveness in the case of core uncovery, it is essential to clarify how the SG depressurization influences the core cooling. The SG depressurization start should have effects on the core cooling by the 
ACC system in PWR cold leg small-break loss-of-coolant accidents under total failure of high-pressure injection system, according to the RELAP5 code study of the related LSTF tests by Asaka, et al. [12]. A time delay for the SG depressurization start will have to be considered if the closure of SG main steam isolation valves should be initiated with some delay. As for the computer code analysis, loss of the primary coolant inventory through the break resulting in core uncovery depends on $\mathrm{Cd}$ (break discharge coefficient). Influences of onset timing of the $\mathrm{SG}$ depressurization and $\mathrm{Cd}$ for two-phase discharge flow onto the core cooling in the 8-in. break case thus were studied by sensitivity analyses, based on the RELAP5 post-test analysis. This paper describes major results from the LSTF tests and the RELAP5 code analyses.

\section{ROSA/LSTF}

The ROSA/LSTF is the world largest integral test facility designed to investigate multi-dimensional thermal-hydraulic responses during PWR transients and accidents. The LSTF simulates a Westinghouse-type four-loop 3,423 MWt PWR by a two-loop system model with full-height and 1/48 in volume. Fig. 2 shows the schematic view of the LSTF that is composed of a pressure vessel, pressurizer and primary loops. Each loop includes an active SG, primary coolant pump, hot and cold legs. Loops with and without pressurizer are designated as loop-A and loop-B, respectively. Each SG is furnished with 141 full-size U-tubes (inner-diameter of $19.6 \mathrm{~mm}$, nine different lengths as shown in Table 1), inlet and outlet plena, boiler section, steam separator, steam dome, steam dryer, main steam line, four downcomer pipes and other internals. Six U-tubes are instrumented for each SG. Instrumented U-tubes designated as tubes 1 and 6 are short tubes (Type 1 in Table 1), tubes 2 and 5 are medium tubes (Type 5) and tubes 3 and 4 are long tubes (Type 9). The hot and cold legs, $207 \mathrm{~mm}$ in inner-diameter, are sized to conserve the volumetric scale $(2 / 48)$ and the ratio of the length to the square root of pipe diameter to better simulate the flow regime transitions in the primary loops [13].

The LSTF core, $3.66 \mathrm{~m}$ in active height, consists of 1,008 electrically heated rods in 24 rod bundles to simulate the fuel rod assembly in the PWR. Axial core power profile is a 9-step chopped cosine with a peaking factor of 1.495 . The radial power profile is achieved by providing three different (high, mean and low) power bundles with a maximum peaking factor of 1.51 for high-power bundle. The LSTF initial core power of $10 \mathrm{MW}$ corresponds to $14 \%$ of the volumetrically-scaled (1/48) PWR nominal core power because of a limitation in the capacity of power supply. The core power after the test initiation then is kept constant at $10 \mathrm{MW}$ for a little while before the core power starts to follow pre-determined power decay

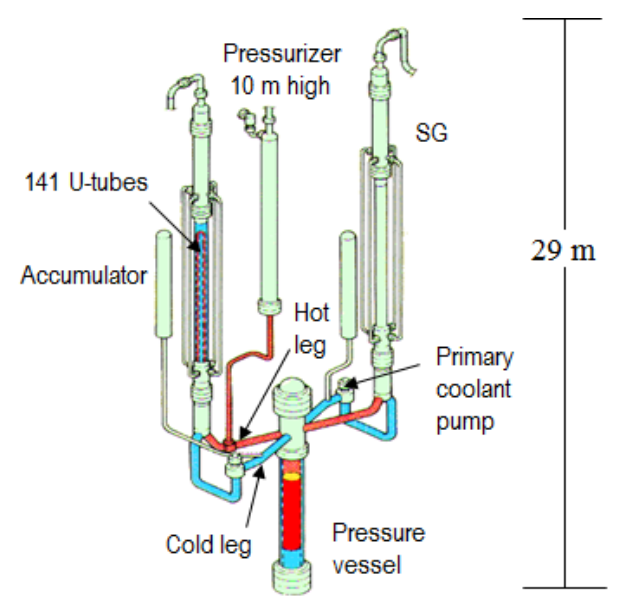

Fig. 2 Schematic view of ROSA/LSTF.

Table 1 Details of LSTF U-tubes in each SG.

\begin{tabular}{llll}
\hline Type & $\begin{array}{l}\text { Straight } \\
\text { length }(\mathrm{m})\end{array}$ & $\begin{array}{l}\text { Number of } \\
\text { tubes }\end{array}$ & Instrumented tubes \\
\hline 1 & 9.44 & 21 & $\begin{array}{l}\text { Two short tubes } \\
\text { (tubes 1 and 6) }\end{array}$ \\
2 & 9.59 & 19 & \\
3 & 9.74 & 19 & \\
4 & 9.89 & 19 & Two medium tubes \\
5 & 10.04 & 17 & (tubes 2 and 5) \\
6 & 10.19 & 15 & \\
7 & 10.34 & 13 & \\
8 & 10.49 & 11 & Two long tubes \\
9 & 10.64 & 7 & (tubes 3 and 4) \\
\hline
\end{tabular}


curve. All the types of emergency core cooling system furnished to the PWR are equipped in the LSTF.

\section{LSTF Test and RELAP5 Code Analysis Conditions}

\subsection{LSTF Test Conditions}

The break for the 8-in. or 4-in. break test was simulated by using a sharp-edge orifice, downwardly mounted flush with the cold leg inner surface in loop-B, as shown in Fig. 3. The orifice size corresponds to 8 -in. or 4-in. diameter break in a PWR as a subject of this study.

Each experiment was initiated by opening a break valve located downstream of the break orifice at time zero. Table 2 shows the major test conditions. Initial steady-state conditions such as pressurizer pressure, fluid temperatures in hot and cold legs were $15.7 \mathrm{MPa}$, $600 \mathrm{~K}$ and $563 \mathrm{~K}$, respectively, according to the PWR conditions. The LSTF core power decay curve after a scram signal was pre-determined based on some calculations of the PWR by Mitsubishi Heavy Industries, Ltd. The LSTF core power was maintained at the initial value of $10 \mathrm{MW}$ for a short while until the scaled core decay power dropped to $10 \mathrm{MW}$ after the scram signal. The LSTF core power started to decay afterwards following the specified core power decay curve. Initial SG secondary-side pressure was raised to $7.3 \mathrm{MPa}$ to limit the primary-to-secondary heat transfer rate to $10 \mathrm{MW}$, while, $6.1 \mathrm{MPa}$ is nominal value in the PWR. Initial SG secondary-side collapsed liquid level was set to $10.4 \mathrm{~m}$ that corresponds to the medium tube height. The rotation speed of a primary coolant pump in each loop was pre-determined considering the characteristics of the PWR pump by Mitsubishi Heavy Industries, Ltd.

Scram and safety injection signals were generated when the pressurizer pressures decreased to $12.83 \mathrm{MPa}$ and $12.13 \mathrm{MPa}$, respectively. The scram signal caused the closure of main steam isolation valves and the termination of feedwater in both SGs as well as the coastdown of primary coolant pumps in both loops.
The SG depressurization valve was simulated by using a sharp-edge orifice to provide steam flow rate when SG secondary-side pressure is $8 \mathrm{MPa}$, which corresponds to almost twice as steam flow rate through a SG relief valve in the reference PWR of the LSTF. The SG depressurization was started by fully opening the depressurization valves in both SGs $10 \mathrm{~s}$ after the safety injection signal, considering the time of SG main steam isolation valves closure. The auxiliary feedwater injection was done into the

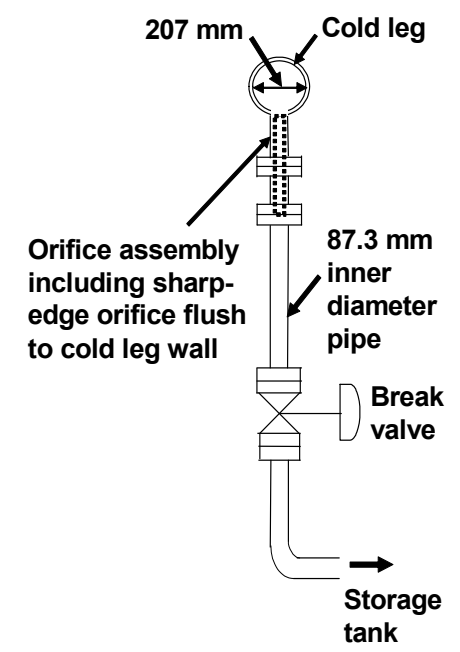

Fig. 3 Schematic view of LSTF break unit.

Table 2 Major test conditions in LSTF tests.

\begin{tabular}{|c|c|}
\hline Item & Condition \\
\hline Initial core power & $10 \mathrm{MW}$ \\
\hline Initial pressurizer pressure & $15.7 \mathrm{MPa}$ \\
\hline Initial hot leg fluid temperature & $600 \mathrm{~K}$ \\
\hline Initial cold leg fluid temperature & $563 \mathrm{~K}$ \\
\hline Initial SG secondary-side pressure & 7.3 MPa \\
\hline $\begin{array}{l}\text { Initial SG secondary-side collapsed } \\
\text { liquid level }\end{array}$ & $10.4 \mathrm{~m}$ \\
\hline Generation of scram signal & $\begin{array}{l}\text { Pressurizer pressure }= \\
12.83 \mathrm{MPa}\end{array}$ \\
\hline Generation of safety injection signal & $\begin{array}{l}\text { Pressurizer pressure }= \\
12.13 \mathrm{MPa}\end{array}$ \\
\hline Start of SG depressurization & $\begin{array}{l}10 \mathrm{~s} \text { after safety } \\
\text { injection signal }\end{array}$ \\
\hline Start of auxiliary feedwater injection & $\begin{array}{l}\text { About } 2 \text { min after } \\
\text { safety injection signal }\end{array}$ \\
\hline Actuation of ACC system & $\begin{array}{l}\text { Primary pressure }= \\
4.14 \mathrm{MPa}\end{array}$ \\
\hline Actuation of LPI system & $\begin{array}{l}\text { Primary pressure }= \\
1 \mathrm{MPa}\end{array}$ \\
\hline $\begin{array}{l}\text { Auxiliary feedwater flow rate for } \\
\text { each SG }\end{array}$ & $0.4 \mathrm{~kg} / \mathrm{s}$ \\
\hline LPI flow rate for each loop & $1.2 \mathrm{~kg} / \mathrm{s}$ \\
\hline
\end{tabular}


secondary-side of both SGs about 2 min after the safety injection signal, considering the delay time of the auxiliary feedwater pumps actuation. The auxiliary feedwater flow rate was at a constant value of $0.4 \mathrm{~kg} / \mathrm{s}$ for each SG.

The ACC system was automatically initiated coolant injection into a cold leg in loop-A only when the primary pressure decreased to $4.14 \mathrm{MPa}$. The ACC system was isolated by the closure of an isolation valve on the ACC injection line when liquid level in the ACC tank decreased to a certain low liquid level to simulate the scaled value of the time-integrated injection flow of the PWR. This system isolation prevents nitrogen gas for pressurization of the ACC tank from entering the primary system. The LPI system was automatically started coolant injection into vessel downcomer through direct vessel injection lines in both loops when the primary pressure decreased to $1 \mathrm{MPa}$. The direct vessel injection line was installed between the LPI line end and downcomer nozzle at a certain elevation level below the cold leg. The LPI flow rate was a constant value of $1.2 \mathrm{~kg} / \mathrm{s}$ for each loop.

\subsection{RELAP5 Calculation Conditions}

A critical flow model by Ransom and Trapp [11], which is implemented in the RELAP5/MOD3.2.1.2 code, is developed for the simulation of a critical flow through a converging-diverging nozzle. For each of the LSTF tests, on the other hand, the break was simulated with a sharp-edge orifice. The post-test analyses were conducted using the RELAP5 code with a two-phase critical flow model proposed by Asaka, et al. [14] to well predict the discharge rate through the sharp-edge orifice. The model employs the Bernoulli incompressible orifice flow equation with $\mathrm{Cd}$ of 0.61 for single-phase discharge liquid [15], and the maximum bounding flow theory for two-phase discharge flow [16]. This flow theory assumes that no phase change occurs at all along the flow, and that the local slip ratio is equal to $\left(\rho_{\text {liquid }} / \rho_{\text {gas }}\right)^{1 / 3}$, where, $\rho$ is the fluid density. Cd of 0.84 was used for single-phase discharge steam [17]. Asaka, et al. [14] have revealed the two-phase break flow rate was somewhat overpredicted by this maximum bounding flow model with $\mathrm{Cd}$ of 0.61 , while, the single-phase break flow rate was well predicted by the above manner, through the post-test analysis of a LSTF test with a sharp-edge orifice to simulate the break. These suggest uncertainties should be included in this maximum bounding flow model for the prediction of two-phase break flow rate. To well predict the two-phase break flow rate, adjustment of $\mathrm{Cd}$ for two-phase discharge flow was tried through some calculations for each of the LSTF tests (to be described in Sections 4.1.2 and 4.2.2).

Fig. 4 shows a noding schematic of LSTF for RELAP5 analysis. The LSTF system is modeled in one-dimensional manner including a pressure vessel, primary loops, pressurizer, SGs and SG secondary-side system. The SG U-tubes were modeled by nine parallel flow channels that correspond to nine different lengths of U-tubes, namely 24 nodes for short-to-medium tubes (straight length of 9.44-9.89 $\mathrm{m}$, four cases in Table 1) and 26 nodes for medium-to-long tubes (straight length of 10.04-10.64 m, five cases), for better prediction of the non-uniform coolant behaviors $[18,19]$. The core was represented by nine equal-height volumes that are vertically stacked according to 9-step chopped cosine power profile along the core length.

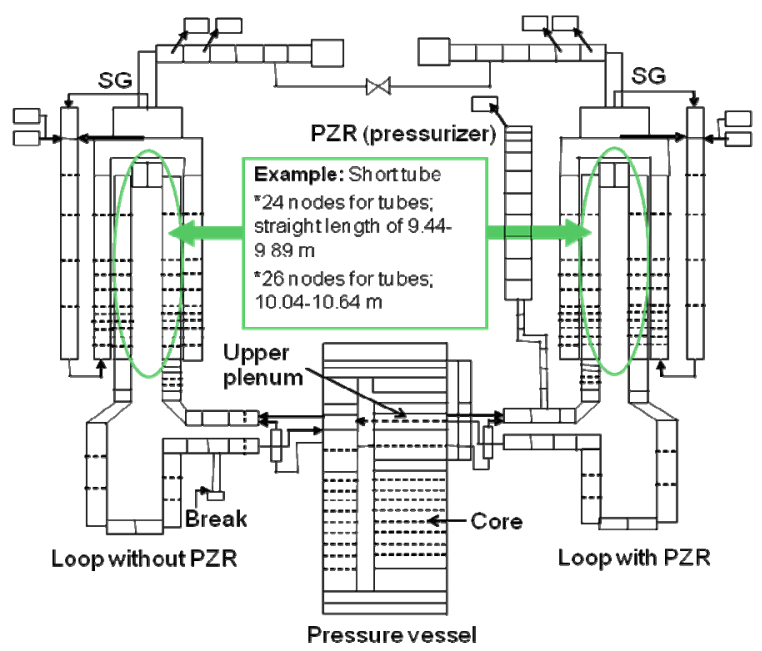

Fig. 4 Noding schematic of LSTF for RELAP5 analysis. 
The radial power distribution then was given considering the peaking factor and the number of high-, mean- and low-power rod bundles. Other initial and boundary conditions were determined according to the LSTF test data.

\section{LSTF Test and RELAP5 Code Analysis Results}

\subsection{8-in. Diameter Break at Cold Leg}

4.1.1 Major Phenomena Observed in 8-in. Break Test

Table 3 summarizes the chronology of major events in the 8-in. break test. Figs. 5-13 show the 8-in. break test results. The time-integrated break flow is evaluated from the liquid level increase in the break flow storage tank. Break flow turned from single-phase liquid to two-phase flow soon after liquid level formed at the cold leg, causing a decrease in the break flow rate (Figs. 5 and 6). The primary pressure started to decrease after the break, while, the SG secondary-side pressure increased up to $8.0 \mathrm{MPa}$ until the SG depressurization start after the closure of main steam isolation valves in both SGs following the scram signal (Fig. 7). The primary pressure decreased to the SG secondary-side pressure, and followed the SG secondary-side pressure afterwards including the depressurization. Liquid level in the cold leg rapidly decreased after loop seal clearing occurred at $200 \mathrm{~s}$, and the cold leg once became empty of liquid (Figs. 6 and 8). The SG secondary-side collapsed liquid level greatly decreased after the SG depressurization, and gradually recovered by the auxiliary feedwater injection into the SG secondary-side (Fig. 9). Collapsed liquid levels monotonically decreased with some different drain rates among the instrumented U-tubes (Fig. 10). The instrumented U-tubes became voided by $180 \mathrm{~s}$.

The core collapsed liquid level began to drop at $190 \mathrm{~s}$ after collapsed liquid level in the crossover leg downflow side started to decrease at $100 \mathrm{~s}$ (Figs. 8 and 11a). The core collapsed liquid level recovered after
Table 3 Chronology of major events in each of LSTF tests.

\begin{tabular}{lll}
\hline \multirow{2}{*}{ Event } & \multicolumn{2}{c}{ Time (s) } \\
\cline { 2 - 3 } & 8 -in. break & 4 -in. break \\
\hline Break valve open & 0 & 0 \\
Generation of scram signal & 13 & 32 \\
Generation of safety injection signal & 16 & 39 \\
Start of SG depressurization & 28 & 50 \\
Start of primary coolant pumps & 44 & 69 \\
coastdown & 45 & 170 \\
Liquid level formation at cold leg & 456 & 175 \\
Start of auxiliary feedwater injection & 156 & None \\
Loop seal clearing & 200 & None \\
Start of core uncovery and heatup & 260 & 321 \\
Stop of primary coolant pumps & 296 & 525 \\
Actuation of ACC system & 328 & None \\
Appearance of PCT (peak cladding & 342 & 2,071 \\
temperature) & 1,287 & 2,231 \\
Isolation of ACC system & 1,503 & 3,009 \\
Actuation of LPI system & 3,013 & 3,050 \\
Core power off & 3,031 & \\
Break valve closure & &
\end{tabular}

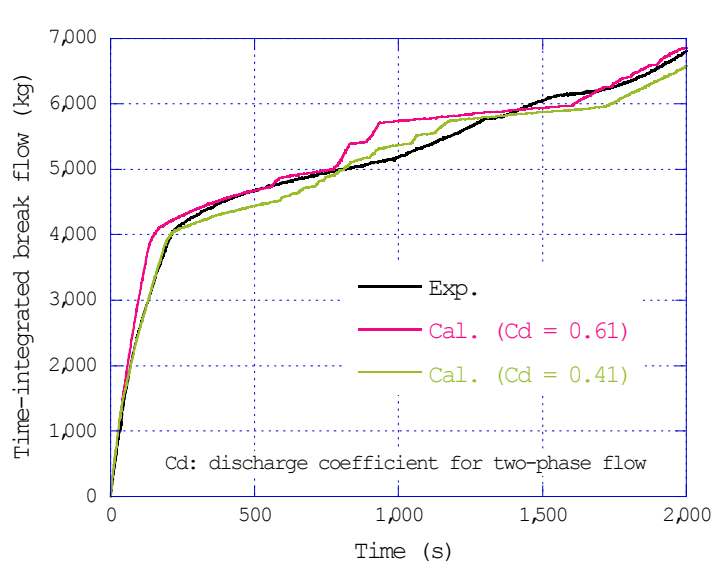

Fig. 5 Measured and calculated results for time-integrated break flow in 8-in. break case.

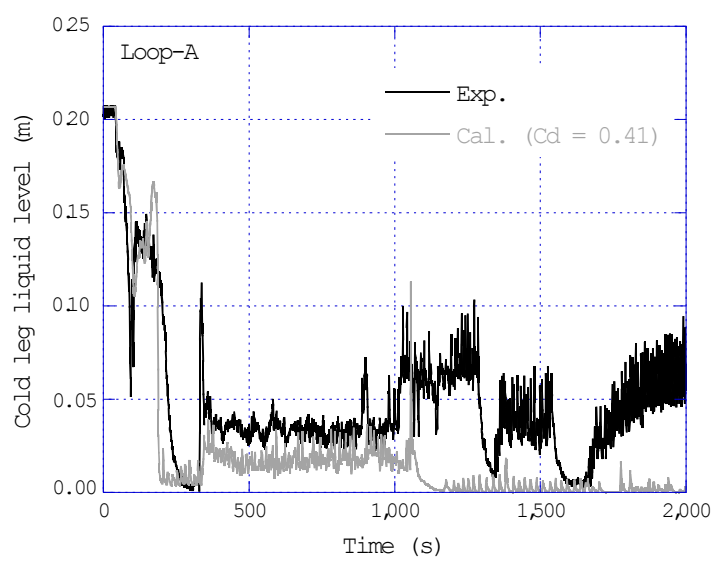

Fig. 6 Measured and calculated results for cold leg liquid level in loop-A in 8-in. break case. 

Generator Secondary-Side Depressurization

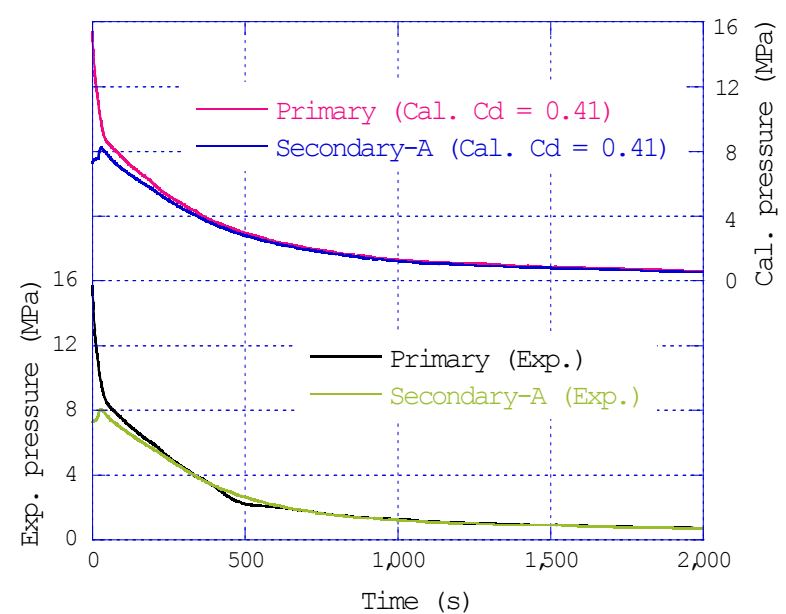

Fig. 7 Measured and calculated results for primary and SG secondary pressures in loop-A in 8-in. break case.

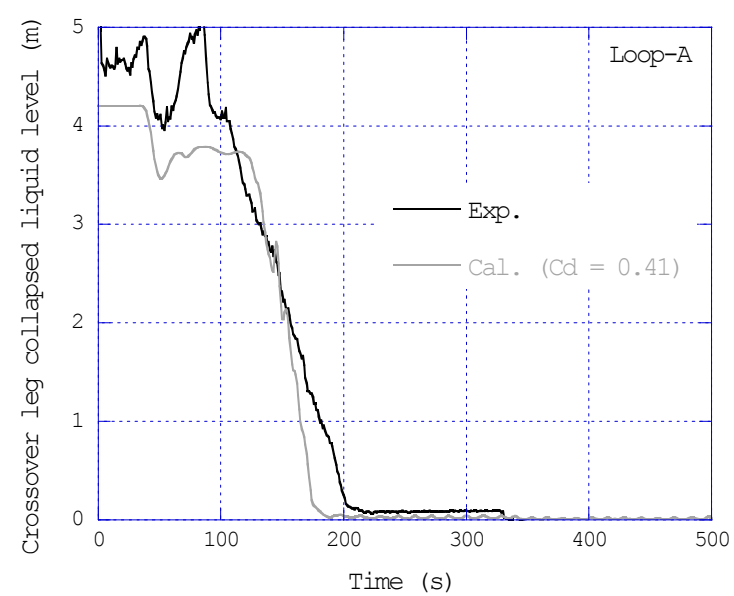

Fig. 8 Measured and calculated results for crossover leg downflow side collapsed liquid level in loop-A in 8-in. break case.

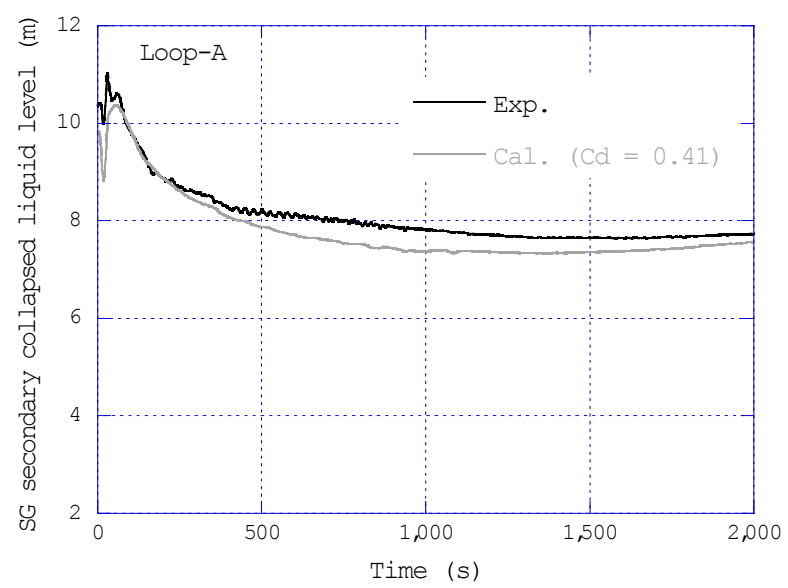

Fig. 9 Measured and calculated results for SG secondary-side collapsed liquid level in loop-A in 8-in. break case.

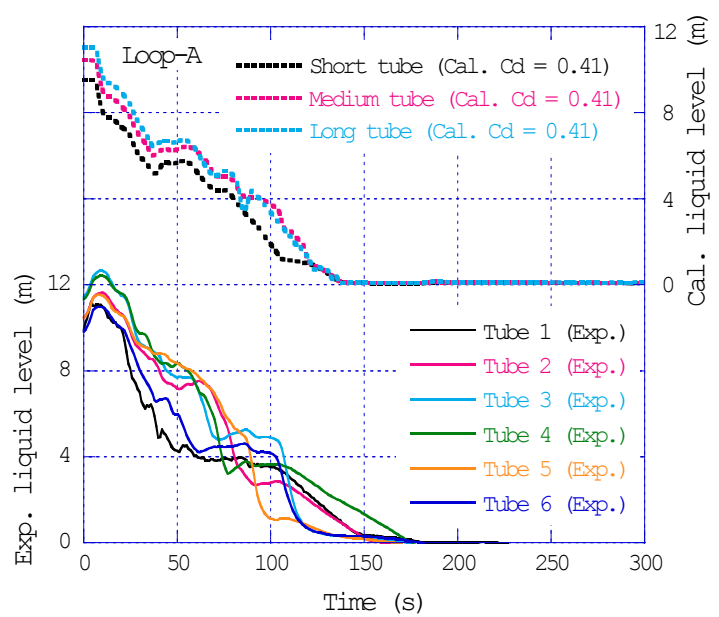

Fig. 10 Measured and calculated results for SG U-tube upflow side collapsed liquid level in loop-A in 8-in. break case.

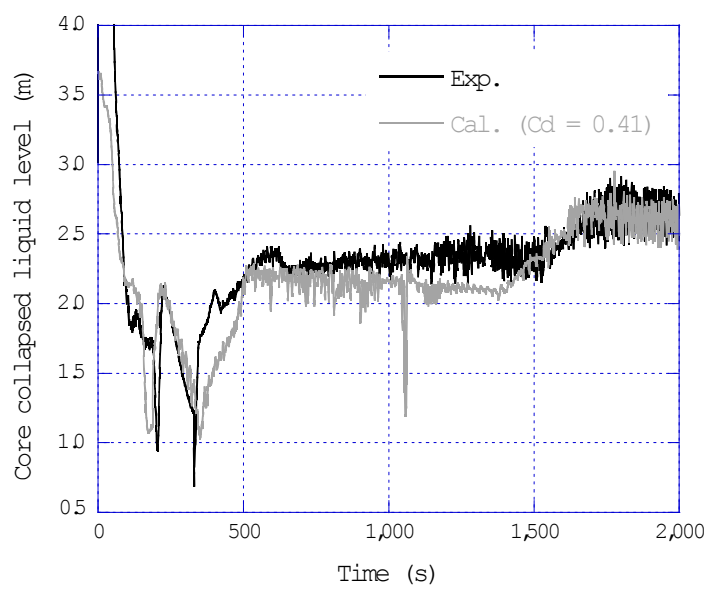

(a)

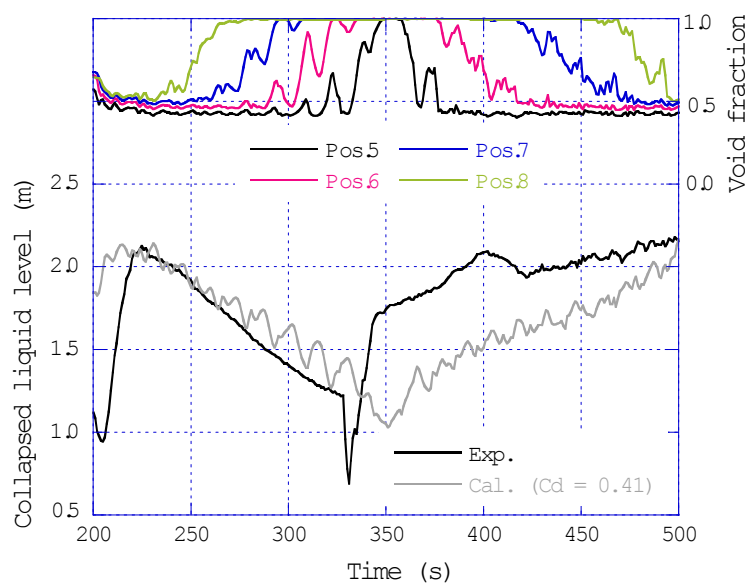

(b)

Fig. 11 Measured and calculated results for core collapsed liquid level as well as calculated core void fraction in 8-in. break case: (a) overall transient $(0-2,000$ s); (b) local transient (200-500 s). 


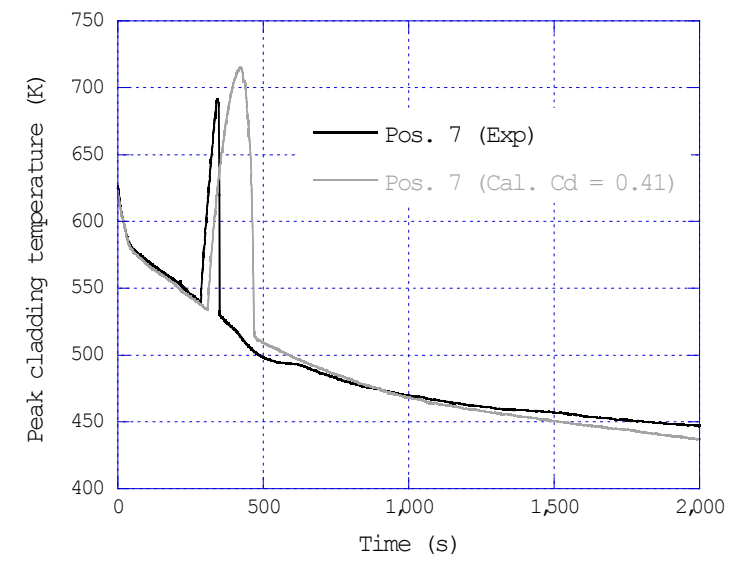

(a)

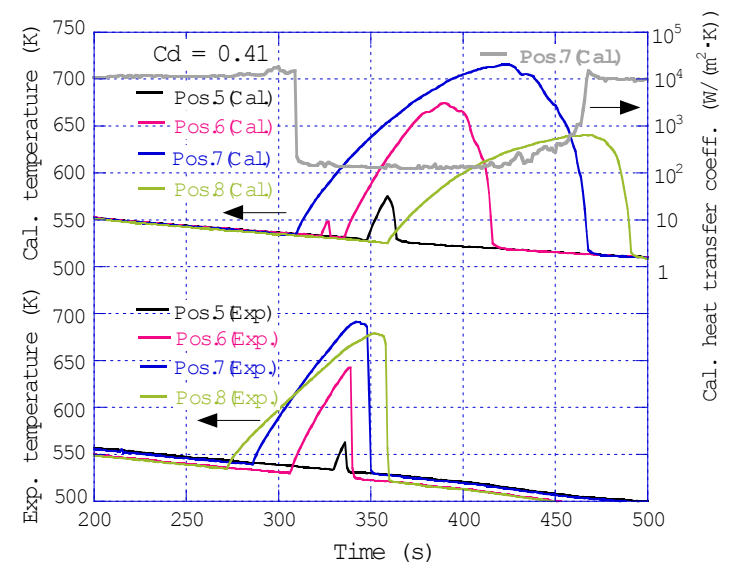

(b)

Fig. 12 Measured and calculated results for cladding surface temperature as well as calculated surface heat transfer of cladding in 8-in. break case: (a) overall transient (0-2,000 s); (b) local transient (200-500 s).

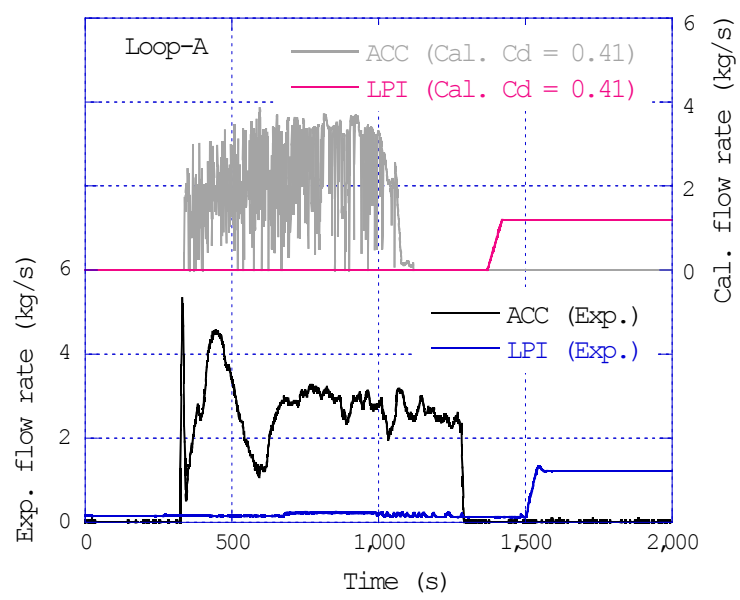

Fig. 13 Measured and calculated results for flow rates of ACC and LPI systems in loop-A in 8-in. break case.

the loop seal clearing occurred at $200 \mathrm{~s}$, which resulted in no increase in cladding surface temperature of simulated fuel rods (Fig. 12a). Core uncovery and heatup took place by core boil-off afterwards following depletion of the primary coolant inventory through the break. The core power was $2.1 \mathrm{MW}$ at $260 \mathrm{~s}$ when the cladding surface temperature started to increase at Position 9 (= about $3.6 \mathrm{~m}$ above the core bottom). The primary coolant pumps were stopped by $296 \mathrm{~s}$, according to the pre-determined pump rotation speed, which affected the primary loop flow rate. The core collapsed liquid level temporarily decreased when the ACC system started coolant injection into a cold leg in loop-A because of steam condensation on the ACC coolant, and recovered thereafter (Figs. 11a and 13). The PCT (peak cladding temperature) was observed at Position 7 (= about $2.6 \mathrm{~m}$ above the core bottom), and was up to $691 \mathrm{~K}$ because of the core liquid level recovery by the ACC coolant injection (Fig. 12b). The whole core was quenched due to core reflooding (Fig. 12b). The core collapsed liquid level greatly increased after the LPI actuation. The cold leg liquid level recovered after the initiation of ACC coolant injection (Figs. 6 and 13). The primary pressure temporarily became lower than the SG secondary-side pressure during the time period around 400-600 s because of large injection flow rate of the ACC system (Figs. 7 and 13). The 8-in. break test was terminated at about 3,000 s when the primary and SG secondary-side pressures decreased to $0.5 \mathrm{MPa}$ with well-cooled core after the LPI actuation.

4.1.2 Comparison of Calculated Results with 8-in. Break Test Data

The RELAP5 code well predicted the break flow rate during single-phase liquid discharge period (Fig. 5). The code, however, overpredicted the break flow rate during two-phase flow discharge period in the case of $\mathrm{Cd}$ of 0.61 for two-phase discharge flow, which is the same as the $\mathrm{Cd}$ for single-phase discharge liquid. The break flow rate became in reasonably-well agreement with in the LSTF test when the Cd was adjusted to be 0.41. Influences of the $\mathrm{Cd}$ for two-phase discharge flow onto the core cooling will be discussed in Section 5.2. 
The code well predicted the overall trend of thermal-hydraulic response observed in the 8 -in. break test by using the $\mathrm{Cd}$ of 0.41 , as shown in Figs. 6-13. The pressure and collapsed liquid level at the SG secondary-side were predicted reasonably well probably due to reasonably-well prediction of steam discharge rate through the SG depressurization valves (Figs. 7 and 9). The code calculated the primary depressurization through the SG depressurization reasonably well, but it failed to reproduce that, the primary pressure temporarily became lower than the SG secondary-side pressure due to smaller ACC flow rate than in the LSTF test (Figs. 7 and 13). The SG U-tube collapsed liquid level was roughly predicted, though with a tendency that the coolant drained with rather same rate among the U-tubes (Fig. 10). The recovery of the core liquid level started earlier in the analysis than in the LSTF test due to earlier loop seal clearing (Figs. 8 and 11a).

The measuring points at Positions 5-8, respectively are located at about $1.8 \mathrm{~m}, 2.2 \mathrm{~m}, 2.6 \mathrm{~m}$ and $3.0 \mathrm{~m}$ above the core bottom, while, locations of the nodes of Positions 5-8, respectively correspond to about 1.6-2.0 m, 2.0-2.4 m, 2.4-2.8 $\mathrm{m}$ and 2.8-3.2 $\mathrm{m}$ above the core bottom. The cladding surface temperature rises when the rod surface is uncovered above two-phase mixture level in the core. When the void fraction is 1 at a node, the core two-phase mixture level appears at just below the node. The calculated cladding surface temperatures at the nodes of Positions 5-8 began to increase at about $350 \mathrm{~s}, 325 \mathrm{~s}$, $310 \mathrm{~s}$ and $360 \mathrm{~s}$, respectively when the void fraction became 1, as shown in Figs. $11 \mathrm{~b}$ and $12 \mathrm{~b}$. The PCT appeared at the node of Position 7 in the analysis, which was equivalent to Position 7 where the PCT was observed in the LSTF test. The PCT was overpredicted because of underprediction of the core collapsed liquid level due to smaller ACC flow rate especially with the start of ACC coolant injection, while, core uncovery and heatup started later in the analysis than in the LSTF test as shown in Figs. 11a, 12a and 13. In the analysis only, significant fluctuation appeared in the ACC flow rate due to influences of steam condensation in the cold leg volume where fluctuation occurred in the pressure (Fig. 13). The maximum cladding surface temperatures at Positions 5 and 6 were overpredicted, while that at Position 8 was underpredicted (Fig. 12b).

In the code, the single-phase steam convection regime is selected when the void fraction is above 0.999 at a node. The convective heat transfer in the single-phase steam flow is calculated by using the maximum value among the estimation based on the correlations obtained by Dittus and Boelter [20], Sellars, Tribus and Klein [21] and Churchill and Chu [22]. Fig. 12b shows the surface heat transfer coefficient of the cladding estimated from the heat flux and the temperature difference between the cladding and coolant at the node of Position 7 where the PCT appeared. The surface heat transfer coefficient of the cladding greatly decreased when the heat transfer mode became the convective heat transfer in the single-phase steam flow. The surface heat transfer coefficient of the cladding turned to increase after an increase in the core collapsed liquid level, which caused a decrease in the cladding surface temperature. The whole core was quenched later in the analysis than in the LSTF test due to the overprediction of the PCT (Fig. 12b). The cold leg liquid level was underpredicted due to earlier termination of ACC coolant injection and inadequate calculation of the liquid level recovery after the LPI actuation (Figs. 6 and 13). The LPI system actuated earlier in the analysis than in the LSTF test due to earlier isolation of ACC system, which caused earlier initiation of great recovery of the core liquid level (Figs. 11a and 13).

\subsection{4-in. Diameter Break at Cold Leg}

4.2.1 Major Phenomena Observed in 4-in. Break Test

The chronology of major events in the 4-in. break 
test is summarized in Table 3. The 4-in. break test results are shown in Figs. 14-21. Break flow became two-phase flow later than in the 8-in. break test because of later liquid level formation at the cold leg due to smaller break flow rate (Figs. 14 and 15). Primary depressurization was slower than in the 8-in. break test due to smaller break flow rate (Fig. 16). The SG secondary-side pressure increased up to $7.9 \mathrm{MPa}$ until the SG depressurization start after the SG main steam isolation valves closure (Fig. 16). The minimum collapsed liquid level in the SG secondary-side was higher than in the 8-in. break test due to later start of the auxiliary feedwater injection (Fig. 17). As for the SG-A U-tubes, collapsed liquid levels began to drop at $350 \mathrm{~s}$ and $200 \mathrm{~s}$, respectively in two medium tubes (tubes 2 and 5 shown in Table 1) but at $100 \mathrm{~s}$ in other instrumented tubes (Fig. 18). The water column drained in the SG U-tubes in non-uniform manner. No significant decrease appeared in collapsed liquid level in the crossover leg downflow side due to smaller break flow rate than in the 8-in. break test, which resulted in no loop seal clearing unlike the 8 -in. break test.

No core uncovery and heatup occurred due to smaller break flow rate than in the 8-in. break test (Figs. 19 and 20). The primary coolant pumps were stopped by $321 \mathrm{~s}$ that is later than in the 8 -in. break test because of later start of the pump coastdown due to later scram signal. The cold leg liquid level recovered after the ACC or LPI actuation (Figs. 15 and 21). The SG U-tube collapsed liquid level once became close to zero, and recovered after the ACC or LPI actuation (Figs. 18 and 21). The primary pressure became slightly higher than the SG secondary-side pressure especially after the initiation of ACC coolant injection (Figs. 16 and 21). The 4-in. break test was terminated at about $3,000 \mathrm{~s}$ when the primary and SG secondary-side pressures decreased to $0.8 \mathrm{MPa}$ with well-cooled core after the LPI actuation.

4.2.2 Comparison of Calculated Results with 4-in. Break Test Data

The break flow rate during single-phase liquid

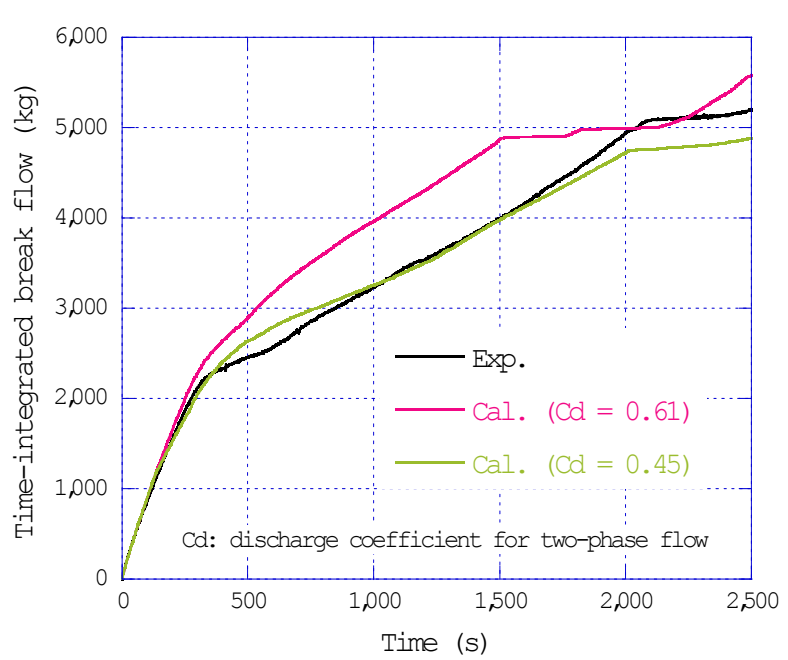

Fig. 14 Measured and calculated results for time-integrated break flow in 4-in. break case.

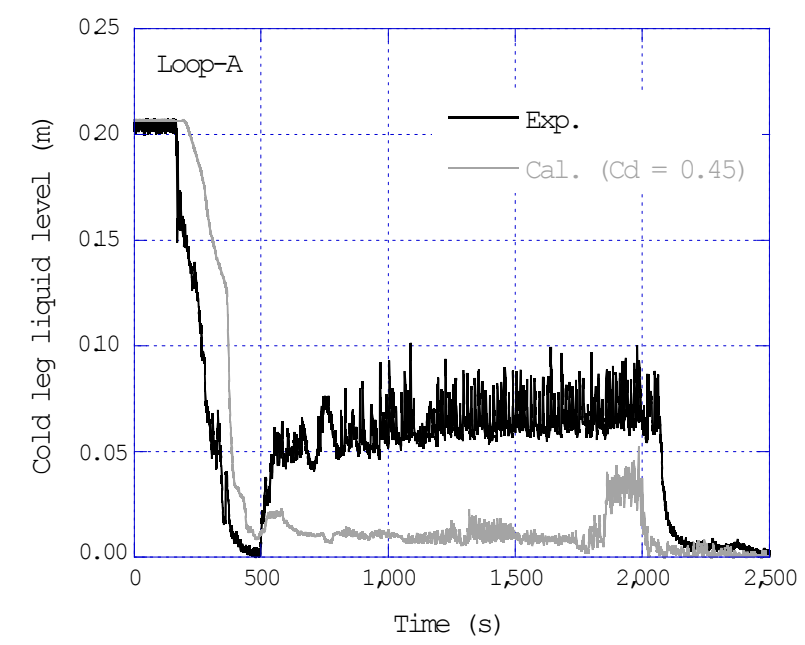

Fig. 15 Measured and calculated results for cold leg liquid level in loop-A in 4-in. break case.

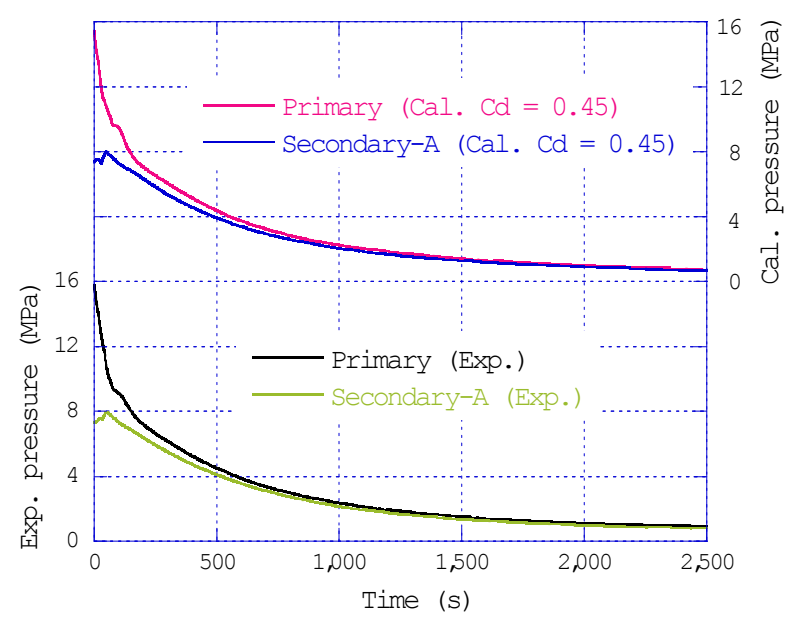

Fig. 16 Measured and calculated results for primary and SG secondary pressures in loop-A in 4-in. break case. 

Generator Secondary-Side Depressurization

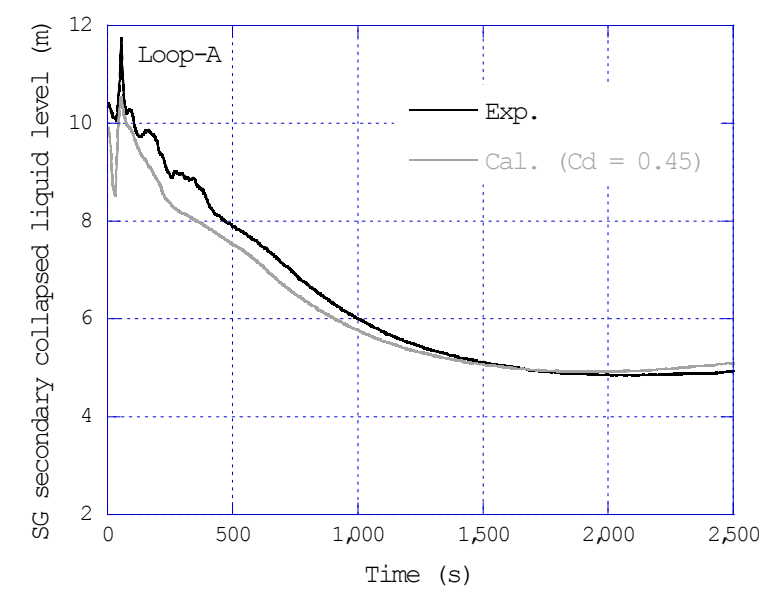

Fig. 17 Measured and calculated results for SG secondary-side collapsed liquid level in loop-A in 4-in. break case.

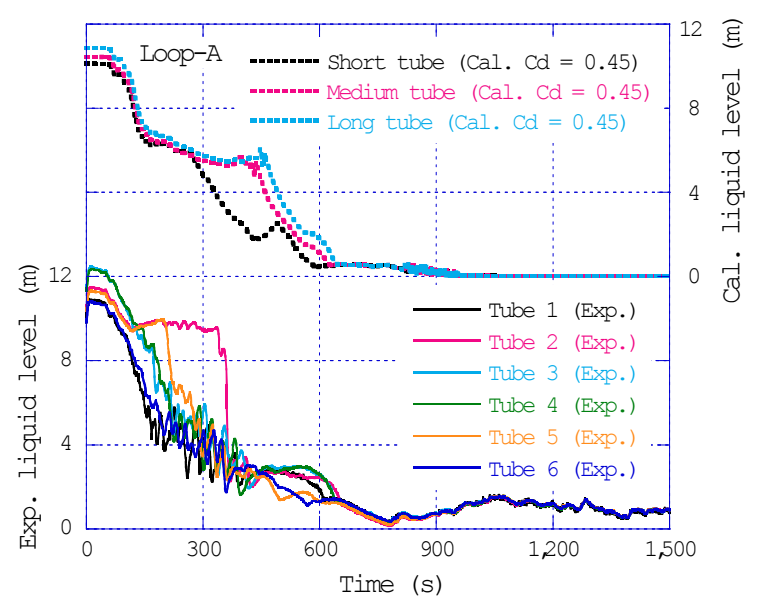

Fig. 18 Measured and calculated results for SG U-tube upflow side collapsed liquid level in loop-A in 4-in. break case.

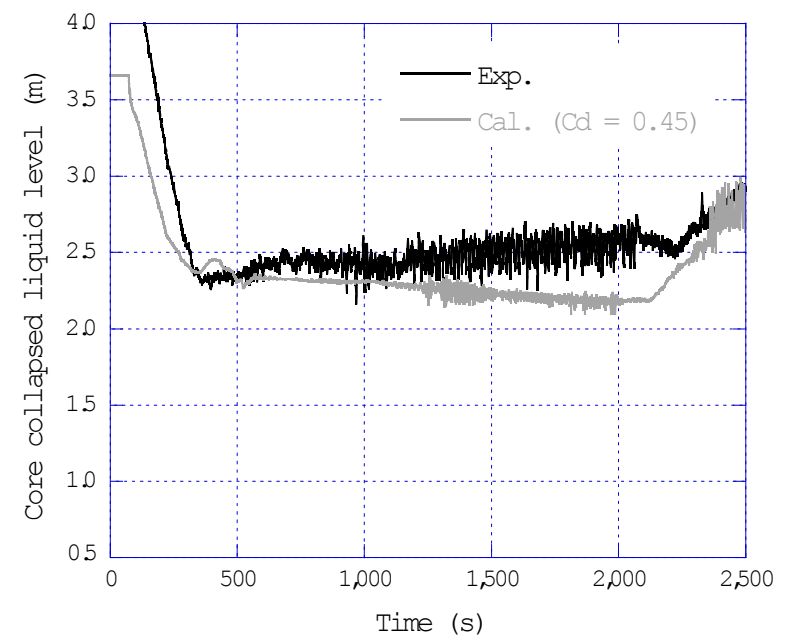

Fig. 19 Measured and calculated results for core collapsed liquid level in 4-in. break case.

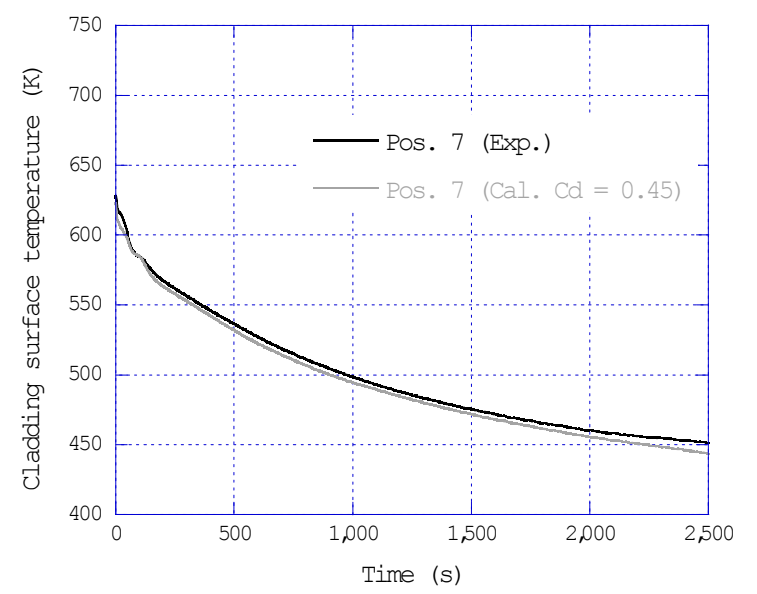

Fig. 20 Measured and calculated results for cladding surface temperature in 4-in. break case.

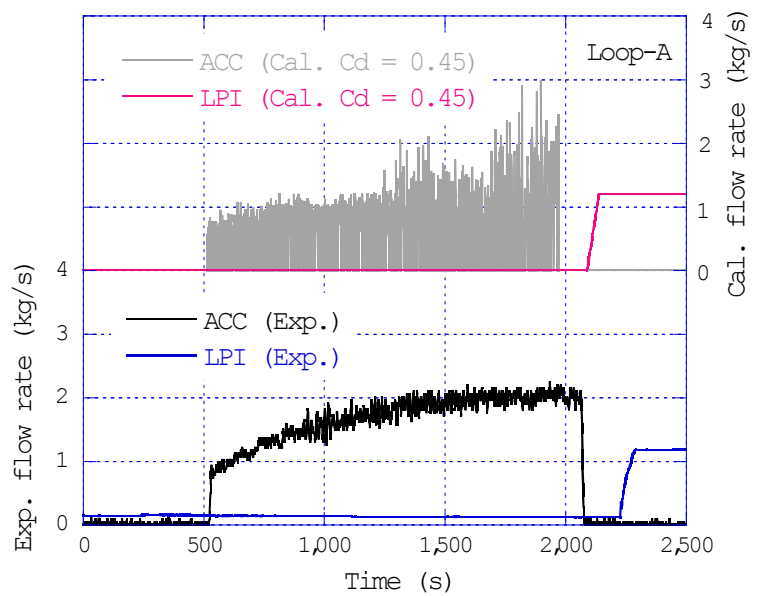

Fig. 21 Measured and calculated results for flow rates of ACC and LPI systems in loop-A in 4-in. break case.

discharge period was well predicted (Fig. 14). The break flow rate during two-phase flow discharge period, however, was overpredicted in the case of $\mathrm{Cd}$ of 0.61 for two-phase discharge flow, which is the same as the $\mathrm{Cd}$ for single-phase discharge liquid. The break flow rate became in reasonably-well agreement with in the LSTF test by adjusting the Cd to be 0.45 . The overall trend of thermal-hydraulic response observed in the 4-in. break test was well predicted by using the $\mathrm{Cd}$ of 0.45 , as shown in Figs. 15-21. The pressure and collapsed liquid level at the SG secondary-side were calculated reasonably well (Figs. 16 and 17) probably due to reasonably-well prediction of steam discharge rate through the SG depressurization valves. The code well predicted that the primary 
pressure became slightly higher than the SG secondary-side pressure especially after the initiation of ACC coolant injection (Figs. 16 and 21). The code reproduced a tendency of the coolant drain in some of SG-A U-tubes (Fig. 18). In the LSTF test, the coolant drained rather slower in tube 2 (one of two medium tubes) than in other instrumented tubes. In the analysis, on the other hand, the collapsed liquid levels in the medium and long tubes decreased slower than in the short tube. The code reproduced no core uncovery and heatup because of reasonably-well prediction of the core collapsed liquid level (Figs. 19 and 20). In the analysis only, there was significant fluctuation in the ACC flow rate (Fig. 21), similar to the 8-in. break case. During the ACC coolant injection period, the cold leg liquid level was underpredicted due to smaller ACC flow rate (Figs. 15 and 21). The LPI actuation was earlier in the analysis than in the LSTF test due to earlier ACC isolation (Fig. 21).

\section{RELAP5 Code Sensitivity Analyses}

Sensitivity analyses were conducted to investigate influences of the onset timing of the SG depressurization and the $\mathrm{Cd}$ for two-phase discharge flow onto the core cooling in the 8-in. break case, based on the RELAP5 post-test analysis.

\subsection{Influences of Onset Timing of SG Depressurization onto Core Cooling in 8-in. Break Case}

A time delay for the SG depressurization start was taken into consideration in the 8-in. break case. The SG depressurization was assumed to start $30 \mathrm{~s}, 50 \mathrm{~s}$ and $70 \mathrm{~s}$ after the safety injection signal, respectively which correspond to $20 \mathrm{~s}, 40 \mathrm{~s}$ and $60 \mathrm{~s}$ later than the LSTF test condition. Employed $\mathrm{Cd}$ for two-phase discharge flow was 0.41 because of reasonably-well prediction of the break flow rate as shown in Fig. 5. Figs. 22-24, respectively show the calculated results up to $1,000 \mathrm{~s}$ for the primary pressure, core collapsed liquid level and PCT in terms of the onset timing of the SG depressurization. The calculated results were compared with the results of the post-test analysis (i.e., the case of SG depressurization being initiated $10 \mathrm{~s}$ after the safety injection signal) as well as those of calculation with no SG depressurization due to malfunction of the $\mathrm{SG}$ valves.

As the SG depressurization started later, core uncovery and heatup took place earlier and the ACC system actuated later because of slower decrease in the primary pressure (Figs. 22-24). Later ACC actuation caused later recovery of the core liquid level (Fig. 23). The calculated PCT, which appeared at the node of Position 7, was $715 \mathrm{~K}, 762 \mathrm{~K}, 814 \mathrm{~K}$ and $892 \mathrm{~K}$ when the SG depressurization was taken $10 \mathrm{~s}, 30 \mathrm{~s}, 50$ $\mathrm{s}$ and $70 \mathrm{~s}$ after the safety injection signal, respectively (Fig. 24). In the calculation with no SG depressurization, the primary pressure became below the SG secondary-side pressure after around $150 \mathrm{~s}$ when the break flow became single-phase steam, and the PCT was $984 \mathrm{~K}$ at the node of Position 7 due to late ACC actuation as compared with the calculation with the SG depressurization (Figs. 22 and 24). As the SG depressurization started later, the whole core was quenched later due to the higher PCT (Fig. 24). Fig. 25 shows the relationships among the SG depressurization start, PCT and ACC actuation time. The influences of a time delay for the SG depressurization start were significant as above onto the PCT because of later ACC actuation.

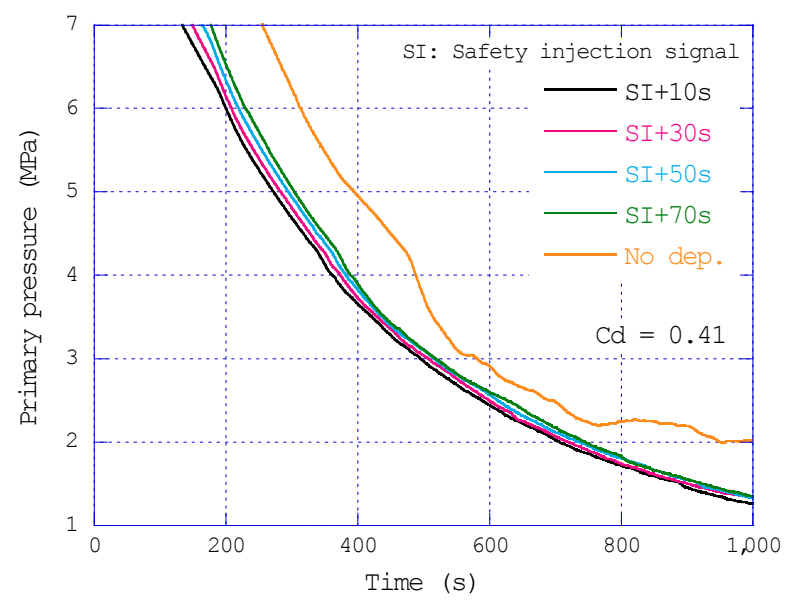

Fig. 22 Onset timing of SG depressurization versus primary pressure in 8-in. break case by calculations. 


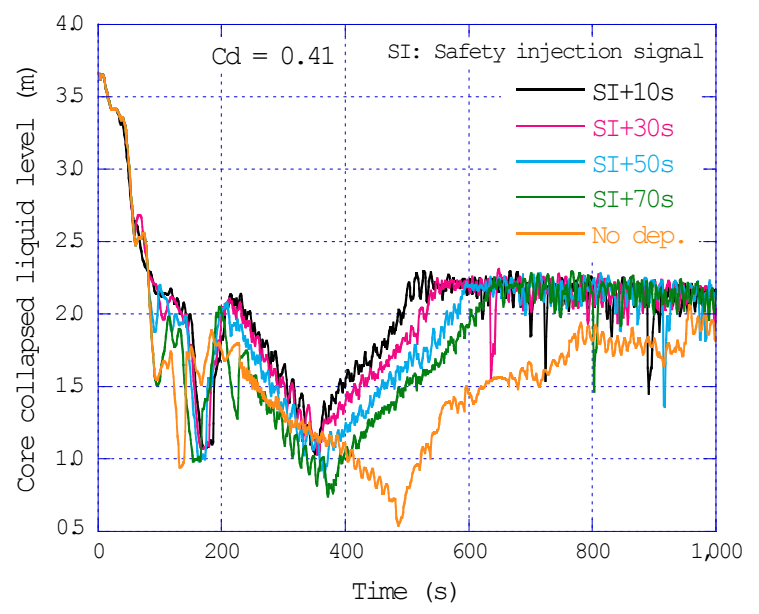

Fig. 23 Onset timing of SG depressurization versus core collapsed liquid level in 8 -in. break case by calculations.

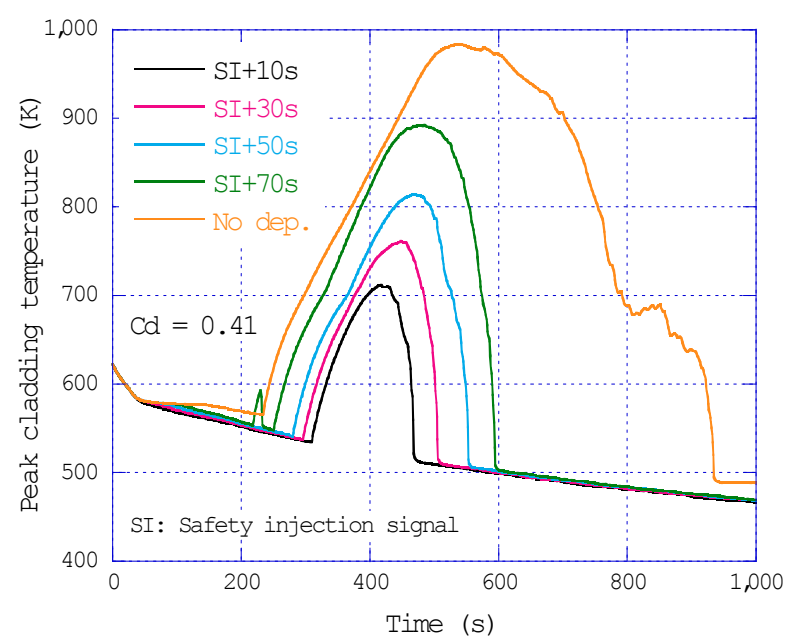

Fig. 24 Onset timing of SG depressurization versus peak cladding temperature in 8-in. break case by calculations.

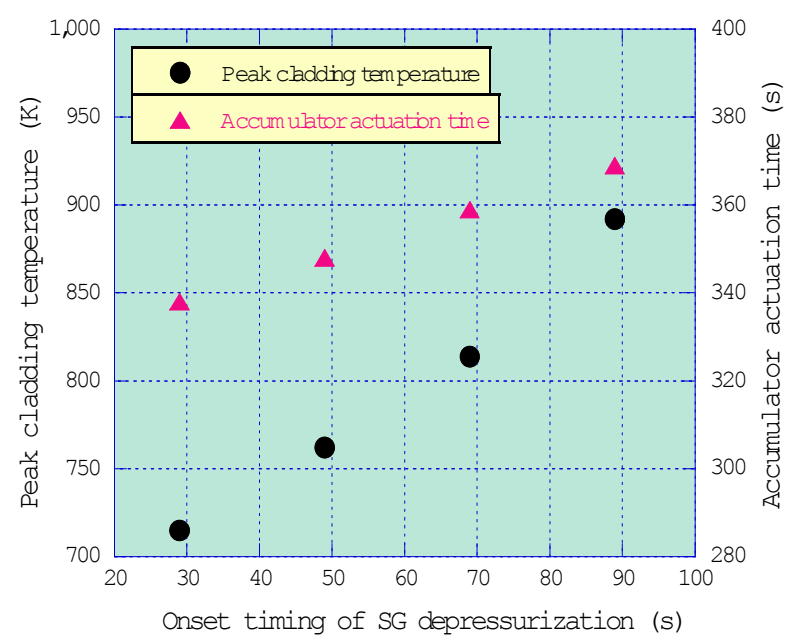

Fig. 25 Relationships among onset timing of SG depressurization, peak cladding temperature and ACC actuation time in 8 -in. break case by calculations.
5.2 Influences of Cd (Break Discharge Coefficient) for Two-Phase Discharge Flow onto Core Cooling in 8-in. Break Case

As mentioned in Fig. 5, the break flow rate during two-phase flow discharge period was overpredicted in the case of $\mathrm{Cd}=0.61$ for two-phase discharge flow while it was predicted reasonably well in the case of $\mathrm{Cd}=0.41$. Used $\mathrm{Cd}$ for two-phase discharge flow was ranging from 0.41 to 0.61 in the 8 -in. break case to clarify the relationships among the $\mathrm{Cd}, \mathrm{PCT}$ and $\mathrm{ACC}$ actuation time. The SG depressurization was assumed to start $10 \mathrm{~s}$ after the safety injection signal, which is the same as the LSTF test condition. Figs. 26-29, respectively show the calculated results up to $1,000 \mathrm{~s}$ for the time-integrated break flow, primary pressure, core collapsed liquid level and PCT in terms of the $\mathrm{Cd}$ for two-phase discharge flow.

Because of larger break flow rate during two-phase flow discharge period with the increased $\mathrm{Cd}$, the primary depressurization was faster thus the ACC system actuated earlier (Figs. 26 and 27). Larger $\mathrm{Cd}$ caused earlier recovery of the core liquid level due to earlier loop seal clearing (Fig. 28). The calculated PCT, which appeared at the node of Position 7, was $715 \mathrm{~K}, 781 \mathrm{~K}, 871 \mathrm{~K}, 890 \mathrm{~K}, 845 \mathrm{~K}$ and $780 \mathrm{~K}$ when the $\mathrm{Cd}$ for two-phase discharge flow was $0.41,0.44$, $0.47,0.50,0.53$ and 0.61 , respectively (Fig. 29). Fig. 30 shows the relationships among the $\mathrm{Cd}$ for two-phase discharge flow, PCT and ACC actuation time. The PCT was lower in the case of $\mathrm{Cd}=0.61$ than in the case of $\mathrm{Cd}=0.50$ because of later core uncovery and heatup by core boil-off due to earlier loop seal clearing as well as more rapidly recovery of the core liquid level due to earlier ACC actuation. The tendency of the calculated PCT suggests that there should be a certain most demanding value of the $\mathrm{Cd}$ for two-phase discharge flow.

The PCT is one of the most important parameters to evaluate the effectiveness of SG secondary-side depressurization as the safety measure for the core cooling. Thermal-hydraulic phenomena, defined as 


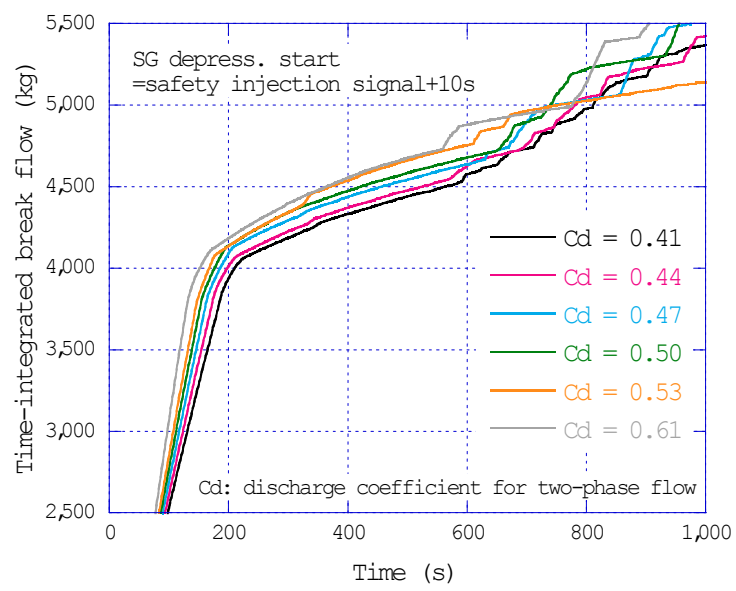

Fig. 26 Break discharge coefficient for two-phase discharge flow versus time-integrated break flow in 8-in. break case by calculations.

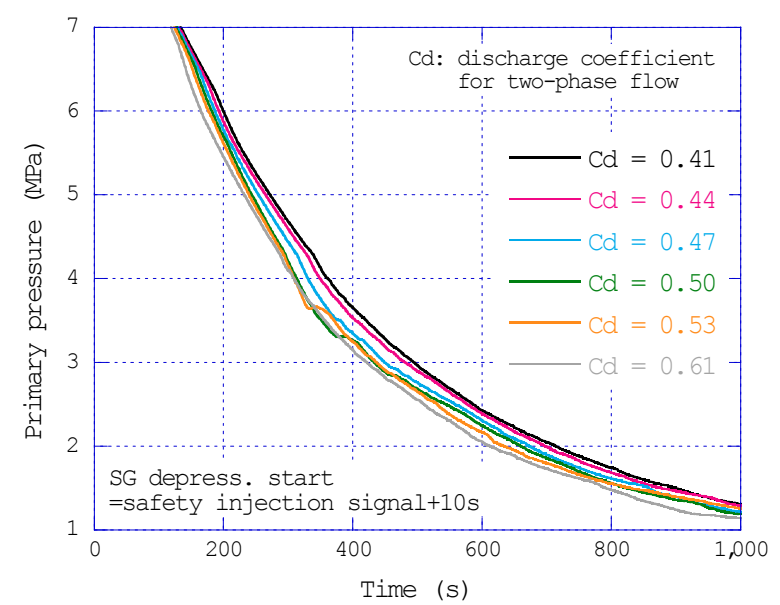

Fig. 27 Break discharge coefficient for two-phase discharge flow versus primary pressure in 8 -in. break case by calculations.

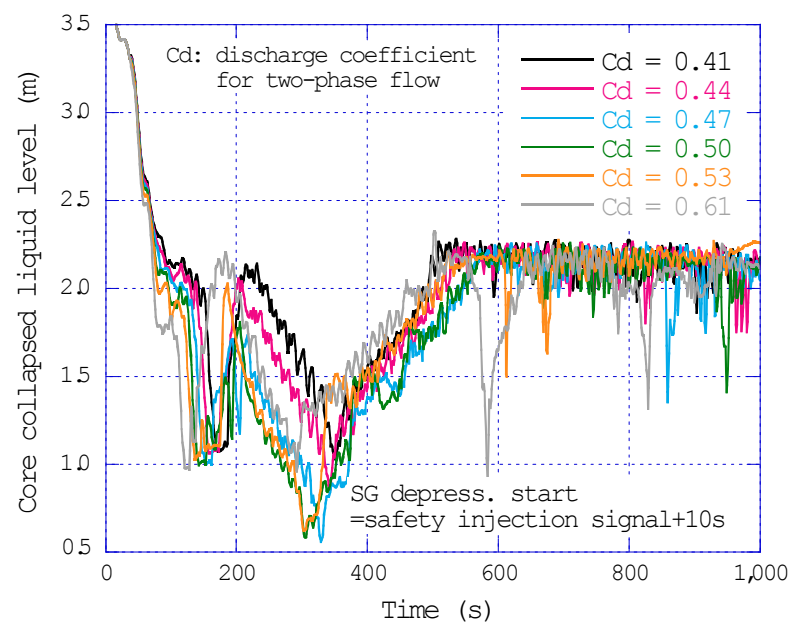

Fig. 28 Break discharge coefficient for two-phase discharge flow versus core collapsed liquid level in 8-in. break case by calculations.

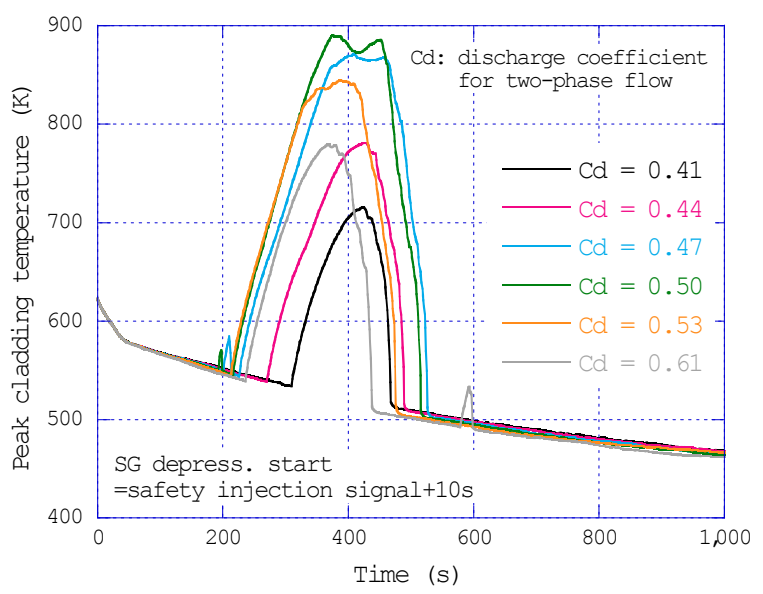

Fig. 29 Break discharge coefficient for two-phase discharge flow versus peak cladding temperature in 8-in. break case by calculations.

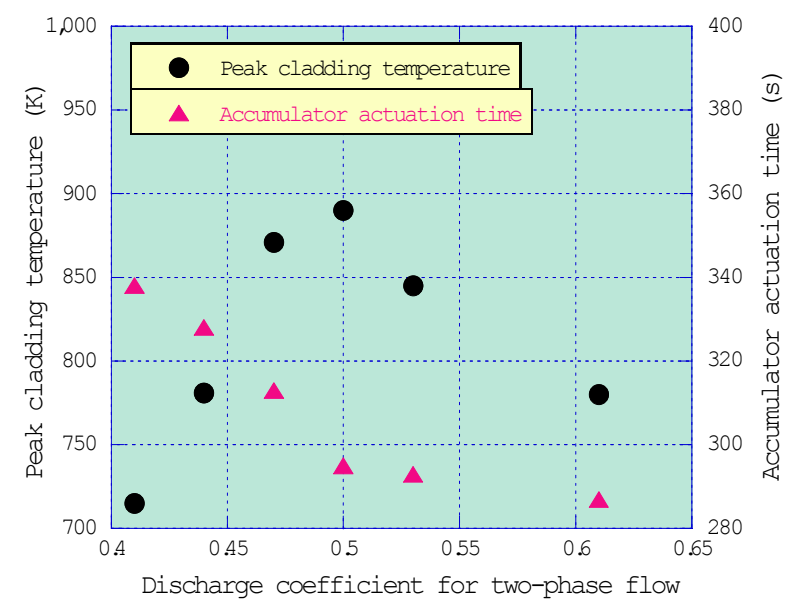

Fig. 30 Relationships among break discharge coefficient for two-phase discharge flow, peak cladding temperature and ACC actuation time in 8-in. break case by calculations.

high-ranked phenomena, may affect the cladding surface temperature significantly depending on the core liquid level behavior [23]. Identifications of the high-ranked phenomena and relevant key parameters were conducted based on the RELAP5 post-test analysis, referring to the ranking of PWR small-break loss-of-coolant accident phenomena [24]. As shown in Table 4, the identified key parameters concerning the high-ranked phenomena include the $\mathrm{Cd}$ for two-phase discharge flow related to critical flow through the break. Other key parameters are core decay power, gas-liquid inter-phase drag in the core, gas-liquid inter-phase heat transfer in the cold leg and in the vessel downcomer, condensation heat transfer in the 
Table 4 High-ranked phenomena and relevant key parameters identified.

\begin{tabular}{|c|c|c|}
\hline Component & Phenomenon & Parameter \\
\hline Break & Critical flow & $\begin{array}{l}\text { Discharge } \\
\text { coefficient through } \\
\text { break }\end{array}$ \\
\hline Fuel rods & Decay heat & Core decay power \\
\hline Core & $\begin{array}{l}\text { Two-phase mixture } \\
\text { level }\end{array}$ & $\begin{array}{l}\text { Gas-liquid } \\
\text { inter-phase drag in } \\
\text { core }\end{array}$ \\
\hline $\begin{array}{l}\text { Cold leg/ACC } \\
\text { system }\end{array}$ & $\begin{array}{l}\text { Steam condensation } \\
\text { on ACC coolant }\end{array}$ & $\begin{array}{l}\text { Gas-liquid } \\
\text { inter-phase heat } \\
\text { transfer in cold leg }\end{array}$ \\
\hline $\begin{array}{l}\text { Vessel } \\
\text { downcomer/LPI } \\
\text { system }\end{array}$ & $\begin{array}{l}\text { Steam condensation } \\
\text { on LPI coolant }\end{array}$ & $\begin{array}{l}\text { Gas-liquid } \\
\text { inter-phase heat } \\
\text { transfer in vessel } \\
\text { downcomer }\end{array}$ \\
\hline SG U-tubes & Steam condensation & $\begin{array}{l}\text { Condensation heat } \\
\text { transfer in SG } \\
\text { U-tubes }\end{array}$ \\
\hline $\begin{array}{l}\text { SG valves for } \\
\text { depressurization }\end{array}$ & Steam discharge & $\begin{array}{l}\text { Discharge } \\
\text { coefficient through } \\
\text { SG valves }\end{array}$ \\
\hline
\end{tabular}

SG U-tubes, and discharge coefficient through the SG depressurization valves. Calculated results by the RELAP5 code include uncertainties in such individual sources as code input data, physical models and user effects (e.g., nodalization). Analyses of the LSTF test on the cold leg small-break loss-of-coolant accident with SG secondary-side depressurization by using best-estimate plus uncertainty methods [25] may be the next step. The $\mathrm{Cd}$ for two-phase discharge flow would then be one of important uncertainty parameters that affect the PCT significantly.

\section{Conclusions}

RELAP5 code analyses were performed on two ROSA/LSTF experiments on PWR safety system that simulated cold leg small-break loss-of-coolant accidents with 8-in. or 4-in. diameter break using SG secondary-side depressurization. The SG depressurization was initiated by fully opening the depressurization valves in both SGs immediately after a safety injection signal. Flow capacity of the SG depressurization valve at a certain SG secondary-side pressure was almost twice as that of a SG relief valve in the reference PWR of the LSTF. Auxiliary feedwater injection was done into the secondary-side of both SGs about 2 min after the safety injection signal. Sensitivity analyses were conducted further to investigate influences of onset timing of the SG depressurization and $\mathrm{Cd}$ for two-phase discharge flow onto the core cooling in the 8-in. break case, based on the RELAP5 post-test analysis. Major results are summarized as follows.

In the 8-in. break test, loop seal clearing occurred and then core uncovery and heatup took place by core boil-off. Core collapsed liquid level recovered after the initiation of accumulator coolant injection, and long-term core cooling was ensured by the actuation of low-pressure injection system. In the 4-in. break test, on the other hand, no core uncovery and heatup occurred due to smaller break flow rate than in the 8 -in. break test.

In the RELAP5 post-test analyses, adjustment of $\mathrm{Cd}$ for two-phase discharge flow predicted the break flow rate reasonably well. The code well predicted the overall trend of the major thermal-hydraulic response observed in the two LSTF tests by the Cd adjustment. The PCT, however, was overpredicted because of underprediction of the core collapsed liquid level due to insufficient prediction of the accumulator flow rate in the 8-in. break case.

The RELAP5 sensitivity analyses indicated that a time delay for the SG depressurization start affected the PCT significantly because of later actuation of the accumulator system in the 8-in. break case. The PCT was also greatly dependent on the $\mathrm{Cd}$ for two-phase discharge flow. High-ranked phenomena and relevant key parameters were identified in the case of cold leg small-break loss-of-coolant accident with SG secondary-side depressurization.

\section{Acknowledgments}

This work was performed by using the LSTF data obtained from contracts among the Kansai Electric Power Co., Inc., Hokkaido Electric Power Co., Inc., Shikoku Electric Power Co., Inc., Kyushu Electric Power Co., Inc. and the Japan Atomic Power Company, the Institute of Applied Energy and 
Mitsubishi Heavy Industries, Ltd. as part of the "Safety Enhancement for LWRs" subsidy program developed by the Agency for Natural Resources and Energy. Authors would like to thank to Messrs. M. Ogawa, A. Ohwada and I. Ohtsu of Japan Atomic Energy Agency for performing the LSTF tests under collaboration with members from Nuclear Engineering Co. as well as Miss K. Toyoda of IX Knowledge Inc. for manipulating the experimental data.

\section{References}

[1] Hirano, M., Yonomoto, T., and Ishigaki, M. 2012. "Insights from Review and Analysis of the Fukushima Dai-ichi Accident." Journal of Nuclear Science and Technology 49 (1): 1-17.

[2] Morimoto, T., Ohnuki, A., and Nishi, H. 2014. "Study on PWR Safety System Using SG Secondary-Side Depressurization." Presented at the NUTHOS-10 (10th International Topical Meeting on Nuclear Thermal-Hydraulics, Operation and Safety), Okinawa, Japan.

[3] Asaka, H., and Kukita, Y. 1995. "Intentional Depressurization of Steam Generator Secondary Side during a PWR Small-Break Loss-of-Coolant Accident." Journal of Nuclear Science and Technology 32 (2): 101-10.

[4] The ROSA-V Group. 2003. "ROSA-V LSTF (Large Scale Test Facility) System Description for the Third and Fourth Simulated Fuel Assemblies, Report JAERI-Tech 2003-037.” Japan Atomic Energy Research Institute.

[5] Takeda, T., Ohwada, A., and Nakamura, H. 2013. "Measurement of Non-condensable Gas in a PWR Small-Break LOCA Simulation Test with LSTF for OECD/NEA ROSA Project and RELAP5 Post-Test Analysis." Experimental Thermal and Fluid Science 51 (November): 112-21.

[6] Takeda, T. 2014. "RELAP5 Analyses of ROSA/LSTF Experiments on AM Measures during PWR Vessel Bottom Small-Break LOCAs with Gas Inflow." International Journal of Nuclear Energy 2014 (September): 1-17.

[7] Aksan, N. 2008. "International Standard Problems and SBLOCA (Small Break Loss-of-Coolant Accident)." Science and Technology of Nuclear Installations 2008: $1-22$.

[8] Clement, P., Chataing, T., and Deruaz, R. 1993. "PWR Accident Management Related Tests: Some BETHSY Results." Presented at the NURETH-6 (6th International
Topical Meeting on Nuclear Reactor Thermal Hydraulics), Grenoble, France.

[9] Umminger, K., Dennhardt, L., Schoen, B., and Schollenberger, S. 2013. "Overview on Test Results from the OECD/NEA PKL 2 Project." Presented at the NURETH-15 (15th International Topical Meeting on Nuclear Reactor Thermal Hydraulics), Pisa, Italy.

[10] Kukita, Y., Yonomoto, T., and Nakamura, H. 1996. "ROSA/AP600 Testing: Facility Modifications and Initial Test Results." Journal of Nuclear Science and Technology 33 (3): 259-65.

[11] RELAP5 Code Development Team. 1995. "RELAP5/MOD3 Code Manual, NUREG/CR-5535 (INEL-95/0174)." Idaho National Engineering Laboratory.

[12] Asaka, H., Anoda, Y., Kukita, Y., and Ohtsu, I. 1998. "Secondary-Side Depressurization during PWR Cold-Leg Small Break LOCAs based on ROSA-V/LSTF Experiments and Analyses." Journal of Nuclear Science and Technology 35 (12): 905-15.

[13] Zuber, N. 1980. Problems in Modeling Small Break LOCA. Ann Arbor: University of Michigan Library.

[14] Asaka, H., Kukita, Y., Yonomoto, T., Koizumi, Y., and Tasaka, K. 1990. "Results of 0.5\% Cold-Leg Small-Break LOCA Experiments at ROSA-IV/LSTF: Effect of Break Orientation." Experimental Thermal and Fluid Science 3 (6): 588-96.

[15] Fauske, H. K. 1965. "The Discharge of Saturated Water through Tubes." Chemical Engineering and Progress Symposium Series 61 (59): 210-6.

[16] Ardron, K. H., and Furness, R. A. 1976. "A Study of the Critical Flow Models Used in Reactor Blowdown Analysis." Nuclear Engineering and Design 39 (2-3): 257-66.

[17] Sallet, D. W. 1984. "Thermal Hydraulics of Valves for Nuclear Applications." Nuclear Science and Engineering 88 (3): 220-44.

[18] Susyadi, and Yonomoto, T. 2005. "Analysis on Non Uniform Flow in Steam Generator during Steady State Natural Circulation Cooling, Report JAERI-Research 2005-011.”Japan Atomic Energy Research Institute.

[19] Takeda, T., Asaka, H., and Nakamura, H. 2012. "RELAP5 Analysis of OECD/NEA ROSA Project Experiment Simulating a PWR Loss-of-Feedwater Transient with High-Power Natural Circulation." Science and Technology of Nuclear Installations 2012: 1-15.

[20] Dittus, F. W., and Boelter, L. M. K. 1930. Heat Transfer in Automobile Radiators of the Tubular Type. Vol. 2. Berkeley: University of California, 443-61.

[21] Sellars, J. R., Tribus, M., and Klein, J. S. 1956. "Heat Transfer to Laminar Flows in a Round Tube or Flat Conduit: The Graetz Problem Extended." Transactions of 
ASME 78 (February): 441-8.

[22] Churchill, S. W., and Chu, H. H. S. 1975. "Correlating Equations for Laminar and Turbulent Free Convection from a Vertical Plate." International Journal of Heat and Mass Transfer 18 (11): 1323-9.

[23] Wilson, G. E., and Boyack, B. E. 1998. "The Role of the PIRT Process in Experiments, Code Development and Code Applications Associated with Reactor Safety Analysis." Nuclear Engineering and Design 186 (1-2): 23-37.
[24] Boyack, B. E., and Ward, L. W. 2000. "Validation Test Matrix for the Consolidated TRAC (TRAC-M) Code." Presented at the International Meeting on Best Estimate Methods in Nuclear Installation Safety Analysis (BE'00), Washington, USA.

[25] Yamaguchi, A., Mizokami, S., Kudo, Y., and Hotta, A. 2009. "Uncertainty and Conservatism in Safety Evaluations based on a BEPU Approach." Presented at the NURETH-13 (13th International Topical Meeting on Nuclear Reactor Thermal Hydraulics), Ishikawa, Japan. 